Poster Mo01, 7th Intemational Conference on the Physics of Highly Charged Ions, Vienna, Austria, September 19-23, 1994

\title{
Ion Charge-State Production and Photoionization Near the K Edge in Argon and Potassium
}

\author{
H.G. Berry, Y. Azuma", P.L. Cowan", D.S. Gemmell, T. LeBrun, and M. Ya Amusia \\ Physics Division, Argonne National Laboratory, Argonne, IL 60439, U.S.A.
}

\begin{abstract}
We have measured the time-of-flight charge distributions of ions of argon and potassium following $\mathrm{x}$-ray absorption at energies near their respective $\mathrm{K}$ edges. We confirm previously observed enhancements of the higher charge states at energies up to $100 \mathrm{eV}$ below the $\mathrm{K}$ edge in argon. The measurements confirm recent calculations suggesting excitation of a virtual 1s state in this energy range.

Present address: KEK Photon Factory, 1-1, Oho, Tsukuba, Japan 305

\section{DISCLAIMER}

This report was prepared as an account of work sponsored by an agency of the United States Government. Neither the United States Government nor any agency thereof, nor any of their employees, makes any warranty, express or implied, or assumes any legal liability or responsibility for the accuracy, completeness, or usefulness of any information, apparatus, product, or process disclosed, or represents that its use would not infringe privately owned rights. Reference herein to any specific commercial product, process, or service by trade name, trademark, manufacturer, or otherwise does not necessarily constitute or imply its endorsement, recommendation, or favoring by the United States Government or any agency thereof. The views and opinions of authors expressed herein do not necessarily state or reflect those of the United States Government or any agency thereof.
\end{abstract}

"Deceased (15 Aug 1994)

\section{MASTER}

DISTRIBUTION OF THIS DOCUMENT IS UNLIMITED

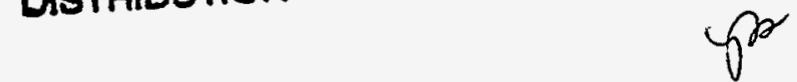




\section{DISCLAIMER}

\section{Portions of this document may be illegible in electronic image products. Images are produced from the best available original document.}




\section{Introduction}

Studies of ion charge state yields following photoexcitation near inner-shell resonances can help to resolve the relative importance of the excitation and relaxation process involved in the gain and loss of energy to the atomic system.

We have studied the production of argon and potassium ions near the thresholds of their respective K-edges. Doppelfeld et al[1] have shown that the average ionic charge $\mathrm{Q}$ (ave) is a linearly increasing function of energy just below the K-edge of argon. The normal resonant ionization behavior would produce a Lorentzian with quadratic energy dependence away from the resonance. Amusia[2] has explained the linear energy dependence as due to the formation of virtual ls state below the edge with consequent further ionization with a $2 \mathrm{~s}$ or higher electron vacancy. Ueda et al[3] have also made a detailed study of this region.

We have made more detailed measurements of the charge state productions for argon ions from 100 volts below the $\mathrm{K}$-edge to above the $\mathrm{KM}$-resonances, as well as some initial measurements in potassium.

\section{Experiment}

The experimental layout is shown in Figure 1. The measurements took place at the Argonne/NIST X24A beam-line of the National Synchrotron Light Source at Brookhaven National Laboratory. The double-crystal monochromator gave a band-pass of about $0.5 \mathrm{eV}$ at $3200 \mathrm{eV}$. The argon experiments utilized a gas nozzle in place of the oven shown for the potassium vapor jet. Time-of-flight measurements of the ions were made utilizing the single bunch operating mode of the NSLS. A multichannel analyzer recorded up to four different charge states simultaneously during each energy scan through the K edge region. Charge states +1 to +7 were recorded during successive scans, normalized using one common charge state in each scan.

\section{Results}

The argon results confirm quite well the measurements of Doppelfeld et al[1]. We estimated the effects of differing efficiencies of the ions reaching the channelplate detector with differing velocities by comparing results with different time-of-flight voltages. It appears that the work of Doppelfeld needs only a small correction to obtain the absolute charge distributions. Our relative charge yield $\mathrm{Q}$ (ave) is slightly higher due to adjustment for the correction of a lower efficiency of the lower charge states. The energy dependence of the average charge state near the $\mathrm{K}$ edge is shown in Figure 2. A major verification of Amusia's calculation[2] is the complete absence of the $4 \mathrm{p}$ resonance in the observed $\mathrm{Q}$ (ave) distribution. The slow increase of the average charge state from $100 \mathrm{eV}$ below threshold is confirmed in Figure 3. The slow linear increase was also observed by Doppelfeld et al[1], and is in accord with Amusia's calculation of excitation of the virtual 1s state.

The individual charge state distributions show the $4 p$ resonances strongly (Figure 4), although it is clear that the slowly increasing energy dependence below threshold can be seen in the higher charge state distributions (4 to 6) below threshold, and is also due to the virtual is excitation. Table I notes the individual charge state productions at energies below $(3192 \mathrm{eV})$ and above $(3220 \mathrm{eV})$ the $\mathrm{K}$ threshold. In the low energy region the higher charge states $(+4$ to +7$)$ 
are already increasing slowly. Further calculations are in progress to show how these charge state ratios can be understood in terms of the virtual excitation model.

Figure 5 shows a small increase in the average charge state in the KM resonance region which must be due to virtual excitations involving multiply-excited states.

The potassium ion spectra are much noisier (Figure 6) due to the much lower target density. In addition, data collection was only possible for a short time (up to 60 minutes), due to contamination of the channelplate detector from the background potassium vapor. Further improvements in the apparatus are underway to allow improved signal ratios. However, even with this reduced signal intensity, Figure 7 shows the same energy dependence of the $Q(a v e)$ as in the argon case.

\section{Acknowledgements}

We acknowledge the technical help of Barry Karlin in the measurements at the NSLS X24A beamline, and of Charles Kurtz and Bruce Zabransky for their design and construction of the alkali oven used in the potassium measurements. This research was supported by the U.S. Department of Energy, Fundamental Interactions Branch, Office of Basic Energy Sciences, Division of Chemical Sciences, under contract number W-31-109-ENG-38 (Argonne).

\section{References}

1. J. Doppelfeld, N. Anders, B. Esșer, F. von Busch, H. Scherer and S. Zinz, J. Phys. B 26, 445 (1993)

2. M.Ya. Amusia, Phys. Lett. A 183, 201 (1993).

3. K. Ueda, E. Shigemas, Y. Sato, A. Yagishita, M.Ukai, H. Maezawa, T. Hayashi and T. Sasaki, J. Phys. B 24, 605 (1991)

Table 1. Charge state populations below and above the 1s threshold (see Fig. 4).

\begin{tabular}{|l|l|l|l|}
\hline Charge state & Yield at $3192 \mathrm{eV}$ & Yield at $3220 \mathrm{eV}$ & Ratio of yields \\
\hline+1 & 115 & 228 & 2.0 \\
\hline+2 & 514 & 2133 & 4.1 \\
\hline+3 & 921 & 3028 & 3.3 \\
\hline+4 & 349 & 9472 & 27.1 \\
\hline+5 & 92 & 4921 & 53.8 \\
\hline+6 & 21 & 1202 & 57.2 \\
\hline+7 & 8 & 142 & $(18)$ \\
\hline & & & \\
\hline
\end{tabular}




\section{Figure Captions}

Figure 1. Ion time-of-flight analyzer with alkali metal oven.

Figure 2. The average charge state in argon through the K-edge.

Figure 3. The average charge state in argon down to $100 \mathrm{eV}$ below the K-edge.

Figure 4. Individual argon ion charge state distributions (note the log scale).

Figure 5. The average charge state in argon near the KM resonances region.

Figure 6. Potassium time-of-flight spectrum

Figure 7. $\mathrm{Q}(\mathrm{ave})$ for potassium through the $4 \mathrm{p}$ resonance. 


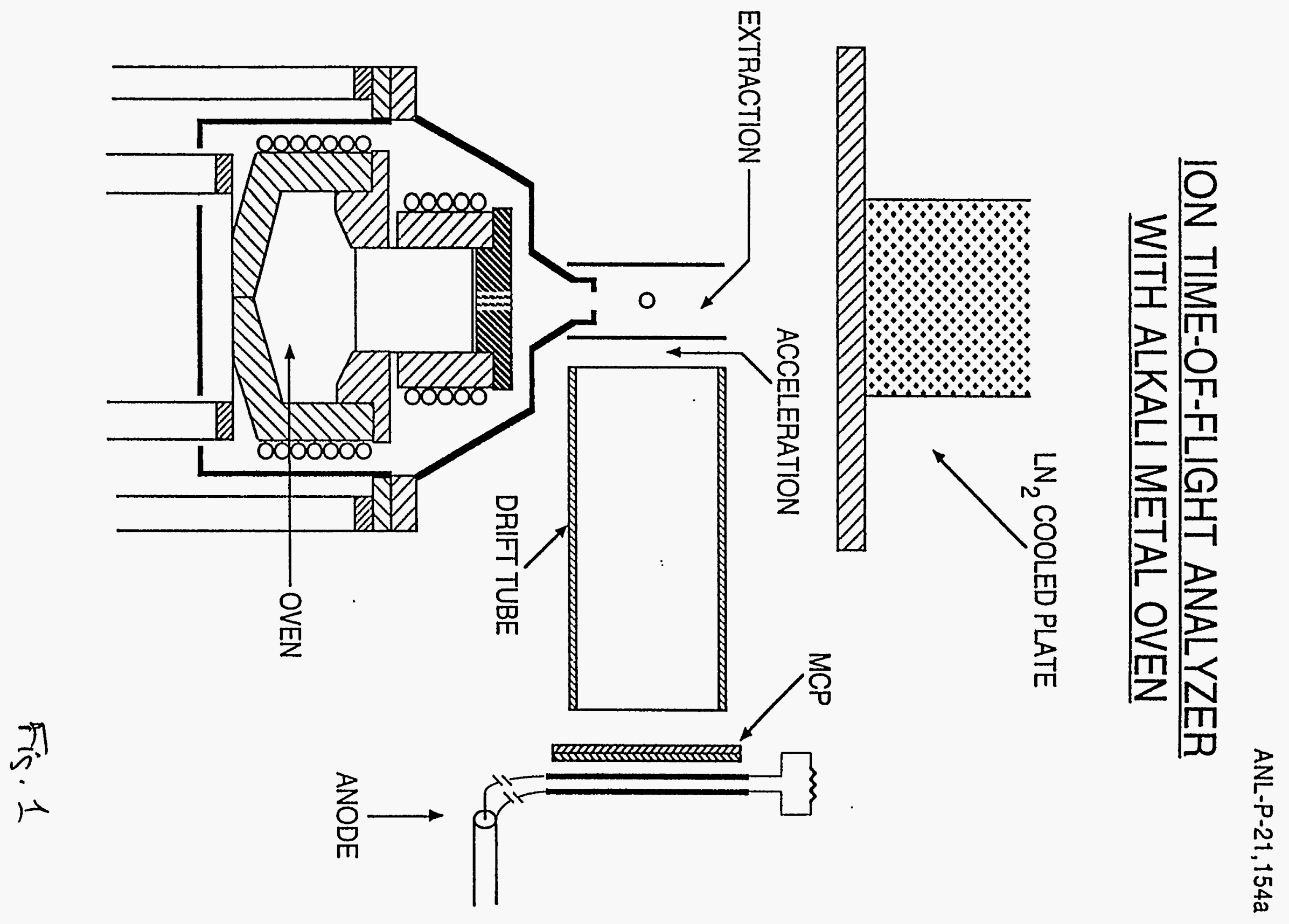




\section{Averaged Argon Charge State (efficiency-adjusted)}

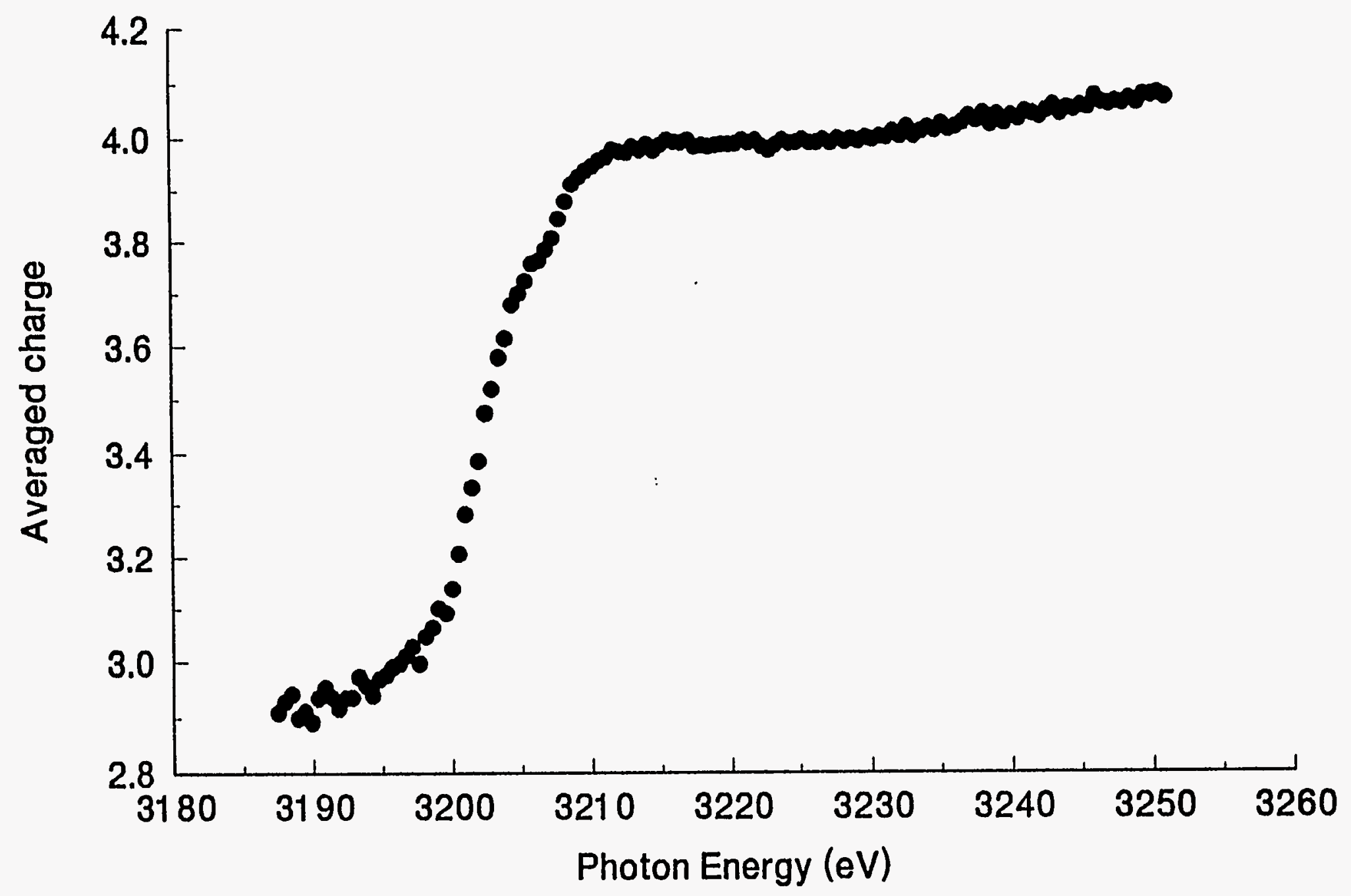




\section{Argon averaged Charge state}

(Below the K-threshold)

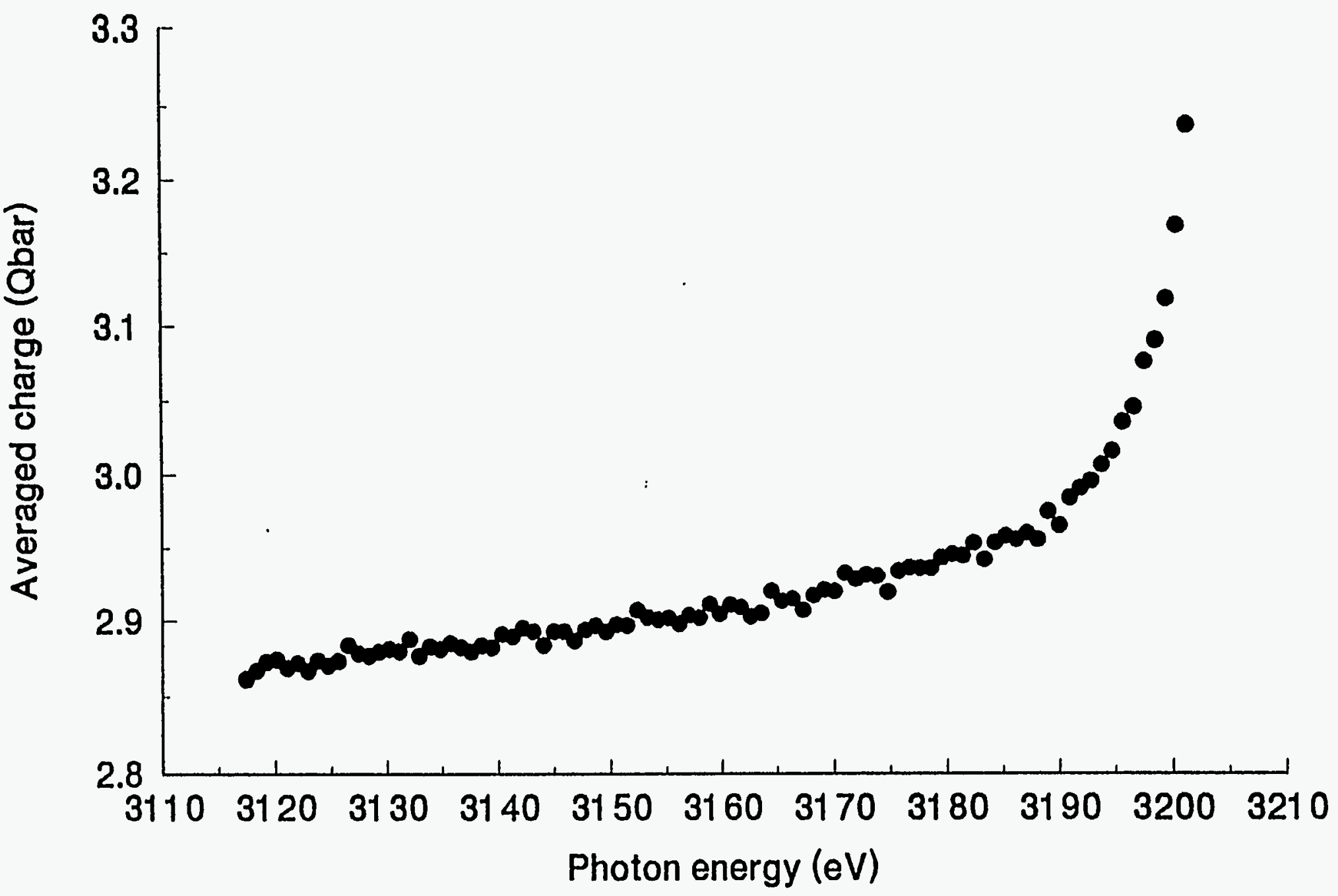




\section{Argon Charge State Yields}

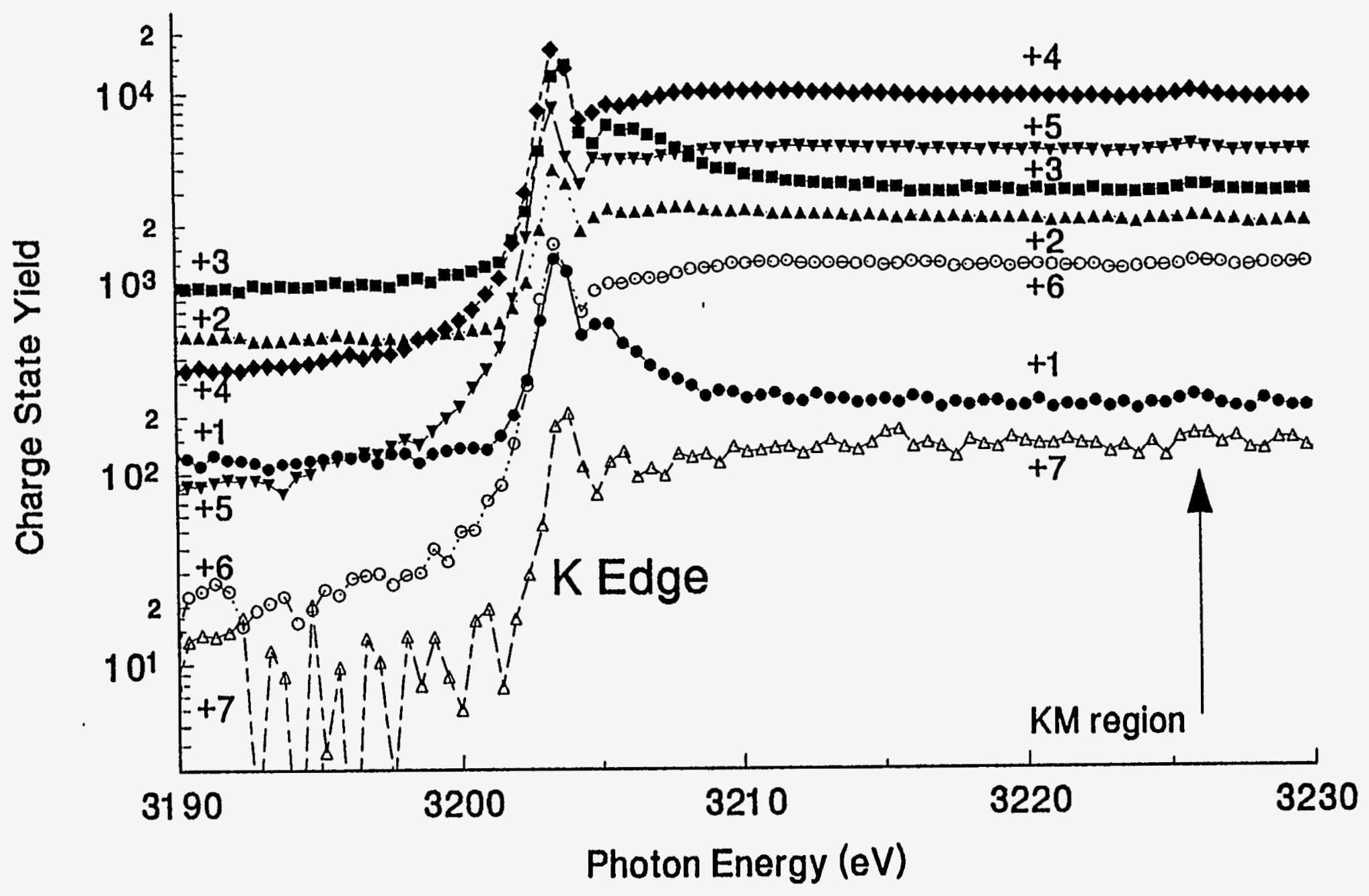




\section{Average Charge state in the $\mathrm{KM}$ region}

$Q B A R=\operatorname{Sum}(Q * N(Q)) / \operatorname{Sum}(N(Q))$

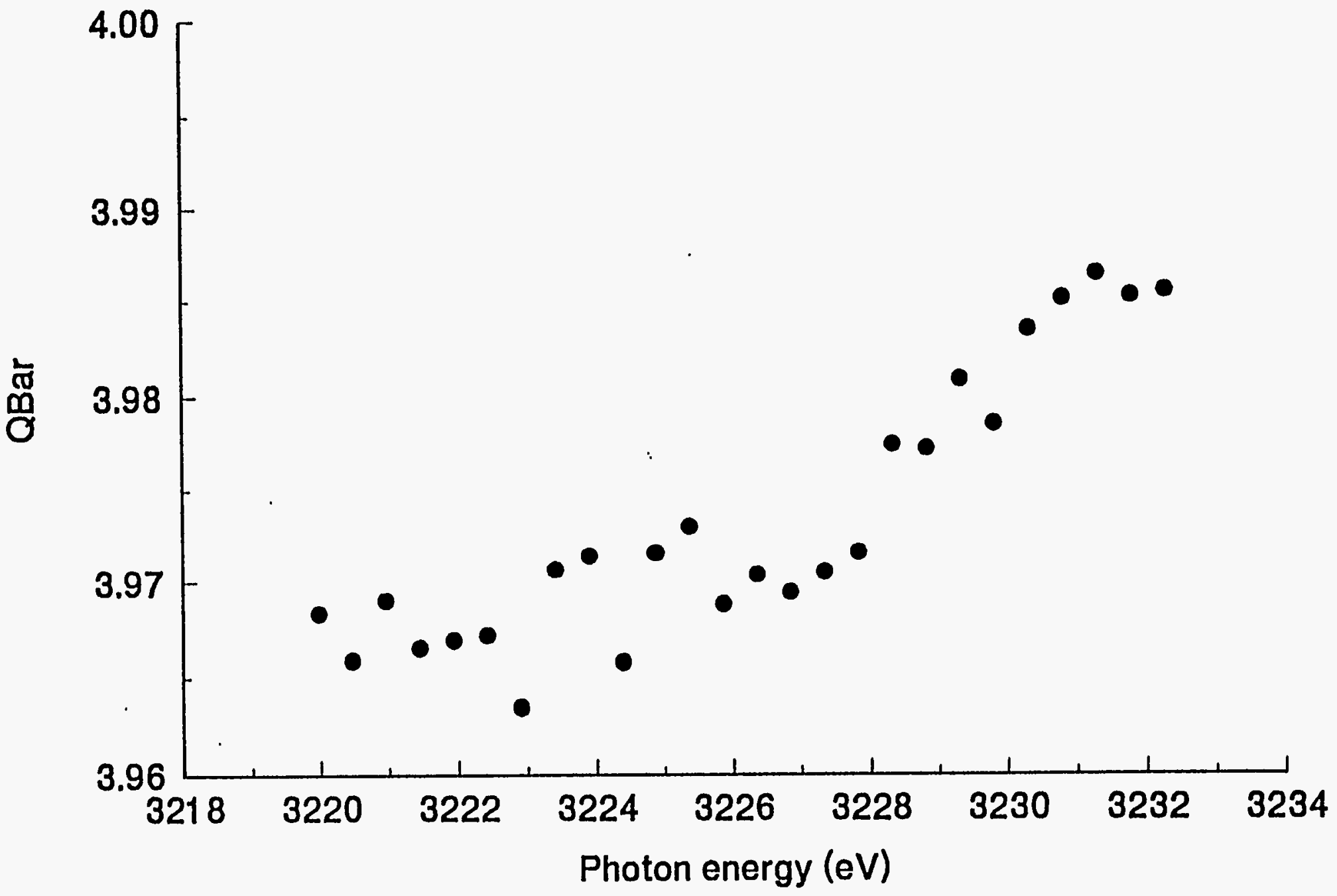




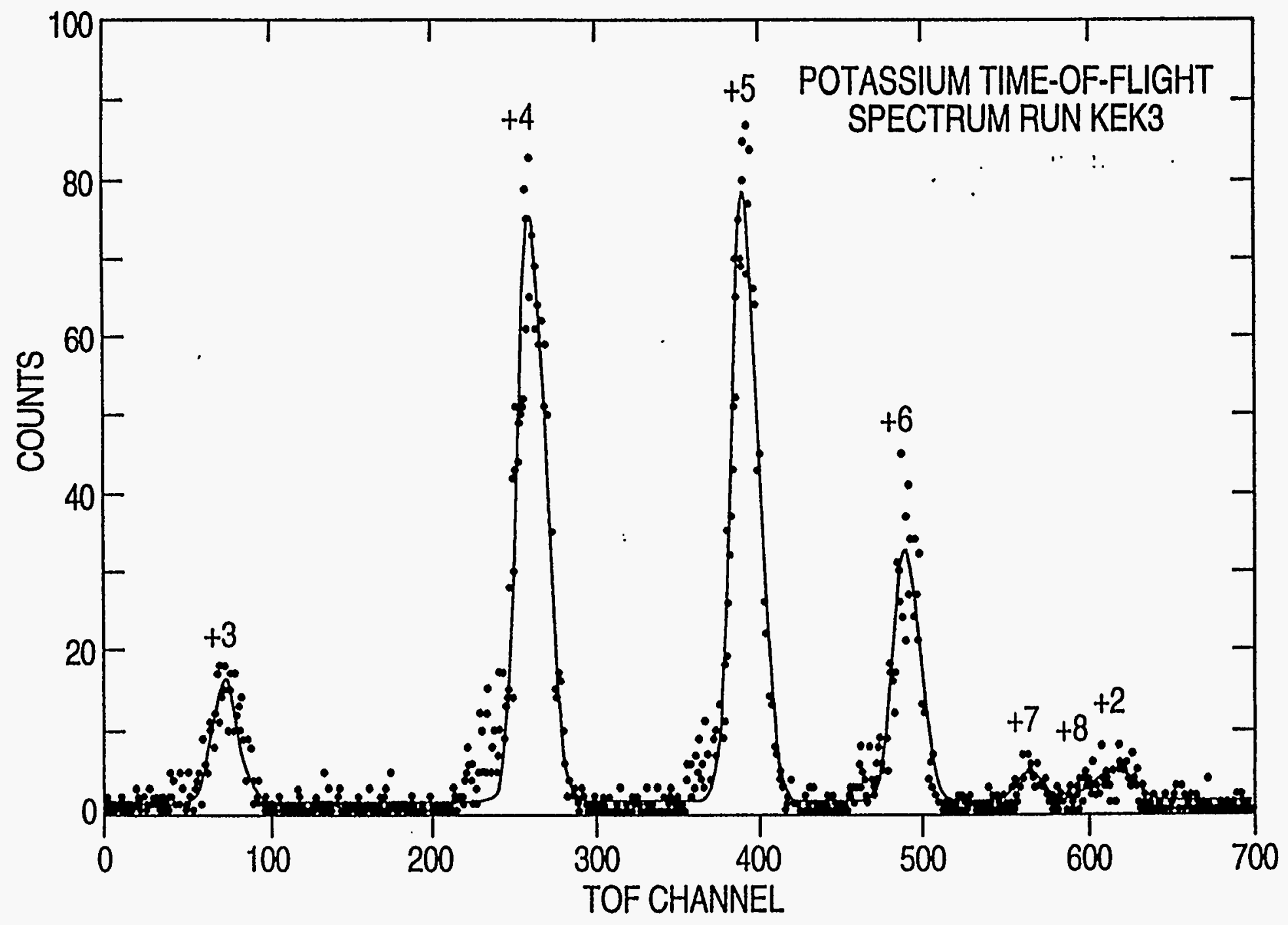




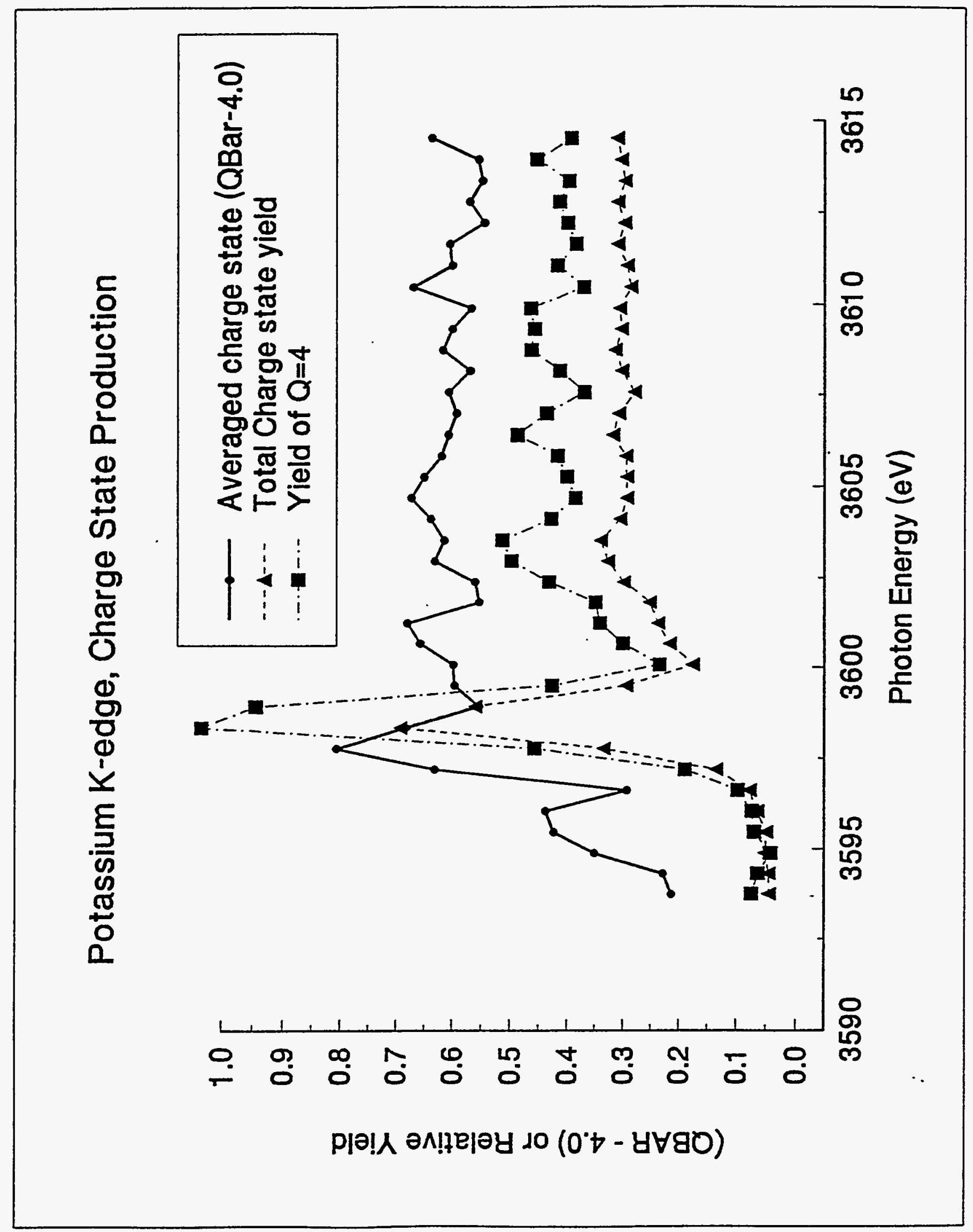

Fis 7 . 